\title{
Transatlantica
}

Revue d'études américaines. American Studies Journal

\section{L'Échange de Clint Eastwood (Changeling, 2008)}

\author{
Jean Foubert
}

\section{OpenEdition}

Journals

Édition électronique

URL : https://journals.openedition.org/transatlantica/4329

DOI : $10.4000 /$ transatlantica.4329

ISSN : 1765-2766

Éditeur

Association française d'Etudes Américaines (AFEA)

\section{Référence électronique}

Jean Foubert, «L'Échange de Clint Eastwood (Changeling, 2008)», Transatlantica [En ligne], 1 | 2009, mis en ligne le 02 septembre 2009, consulté le 17 septembre 2021. URL : http://

journals.openedition.org/transatlantica/4329; DOI : https://doi.org/10.4000/transatlantica.4329

Ce document a été généré automatiquement le 17 septembre 2021.

\section{(c)}

Transatlantica - Revue d'études américaines est mise à disposition selon les termes de la licence Creative Commons Attribution - Pas d'Utilisation Commerciale - Pas de Modification 4.0 International. 


\title{
L'Échange de Clint Eastwood (Changeling, 2008)
}

\author{
Jean Foubert
}

1 Lors de la sortie de Changeling (prix spécial du $61^{\mathrm{e}}$ festival de Cannes), le réalisateur Clint Eastwood et son scénariste J. Michael Straczynski ont souvent insisté sur le fait que bien qu'improbable, le drame de l'hérö̈ne du film, Christine Collins (Angelina Jolie), n'était pas pour autant le produit de l'imagination d'un écrivain de polar inspiré, mais, comme le confirme le complément du titre de l'œuvre, une histoire vraie. Loin d'être le nouvel avatar du cycle des légendes urbaines, Changeling (au même titre que le Black Dahlia écrit par James Ellroy) est effectivement une true-crime story, le récit d'événements criminels advenus entre la fin des années 20 et le milieu des années 30 à Los Angeles et ses environs (notamment dans l'Inland Empire, l'intérieur des terres californien). Le souci apparent de coller à la réalité du fait divers dans toute sa complexité «encyclopédique » est attesté par le travail maniaque de documentation effectué par J.M. Straczynski (qui a collecté pour l'écriture du scénario quelque 6000 pages d'informations)

2 Alors, quid de ce tall-tale d'une effrayante authenticité? Un jour de mars 1928, Christine, jeune mère célibataire employée par une compagnie téléphonique installée dans le centre administratif de Los Angeles, rentre chez elle, pour découvrir que son fils chéri (Walter, neuf ans) a disparu. Prévenue en soirée, la police, fidèle à sa procédure, ne lance des recherches qu'au lendemain de la disparition. Le temps des investigations suit son cours, quelques mois s'écoulent avant qu'un garçon prétendant être Walter soit retrouvé, puis reconduit à la gare de Los Angeles où, moment joyeux des retrouvailles officielles oblige, patientent policiers, journalistes et une femme alors incapable d' exprimer publiquement son intime certitude que cet enfant n'est pas le sien. Soutenue dès le début de l'affaire par le fort naturellement austère révérend presbytérien Gustav Briegleb (John Malkovich), l'héroïne ne tarde toutefois pas à se rebiffer et réclame de l'institution une nouvelle enquête, qui sera vite expédiée. Pour éviter de se désavouer publiquement et pour ne pas ajouter aux accusations de corruption qui l'accable une preuve flagrante de son incompétence, le pouvoir policier décide alors d'emprisonner 
Christine dans un hôpital psychiatrique. Ce geste inique est suivi d'un sombre rebondissement: Walter compterait parmi les nombreux enfants victimes d'un serialkiller (Gordon Northcott interprété par un formidable Jason Butler Harner) sévissant dans un ranch délabré du comté de Riverside inopinément inspecté par le détective Lester Ybarra (Michael Kelly). Délivrée de son internement forcé, Christine engage une action judiciaire contre la municipalité et la police de Los Angeles. La hiérarchie policière est, au bout du compte lourdement blâmée, la procédure d'internement psychiatrique sensiblement réformée, tandis qu'interpellé au Canada, Gordon Northcott est condamné à la peine de mort par pendaison. Quand s'achève le film, rien ne prouve cependant avec certitude que Northcott ait massacré le petit Collins et le film s'achève sur l'espoir qu'il ait pu lui échapper.

3 Produite avec des moyens colossaux, la restitution événementielle du fait divers se double d'une reconstitution minutieuse du Los Angeles de l'époque (à titre d'exemple, J.M. Straczynski réécrivit une scène du scénario de tournage pour y effacer une référence anachronique faite au jeu de Scrabble). Parmi les moyens mis en œuvres par l'équipe de production, des bâtiments emblématiques de l'architecture des années 20 furent rénovés, la façade de l'hôtel de ville de Los Angeles fut retouchée à l'aide d'effets spéciaux et une réplique du célèbre tramway rouge de la Pacific Electric Railway fut remise en circulation avec cent-cinquante voitures vintage et près de mille figurants en costume d'époque. Miroir de la croissance de l'engagement des femmes dans la vie professionnelle, l'activité bourdonnante du central téléphonique où travaille Christine est très habilement restituée.

4 Peut-on pour autant parler de réalisme documentaire à propos du cinéma de $C$. Eastwood ? Pas si sûr, ou plutôt pas si simple, comme en témoigne le titre du film et sa traduction. Emprunté aux mythes et légendes de l'Europe occidentale, le terme "changeling » désignant l'enfant des fées substitué à celui qu'elles ont volé ne possède pas d'équivalent direct en français, où le terme d'«échange » désigne l'opération au terme de laquelle une chose est reçue en contrepartie d'une autre. Au-delà de la difficulté de traduction, l'écart entre les termes est épistémologique : le titre français inscrit distinctement l'œuvre dans le registre du récit réaliste là où le titre anglaisle situe dans celui du merveilleux.

5 L'objet de C. Eastwood n'est pas simplement de dénoncer la brutalité de l'institution policière et l'injustice faite aux femmes dans l'Amérique des années 20 : l'affaire Collins a été choisie parce qu'elle est, pour une œuvre filmique, un sujet idéal. Dès l'ouverture, le film renonce au pastiche de l'image noir et blanc du cinéma des année 20, une option qui aurait été possible. La recréation de l'occurrence historique telle que la pratique C. Eastwood a recours à des procédés de stylisation qui subliment la matière brute du fait divers en œuvre cinématographique de fiction, jusqu'à l'hyperréalité. Ainsi, par son pathos, ses excès relevant parfois du registre gore ou l'invraisemblance de ses péripéties, Changeling manifeste l'évidence d'une forme mélodramatique que souligne également l'organisation rythmique du récit (imprévu d'une conversation qui retarde Christine le jour de l'enlèvement, son sauvetage in extremis à l'hôpital psychiatrique, etc.). Conte de fées pour adultes assorti d'un tueur d'enfants aux airs de croquemitaine rigolard et jouissif, Changeling est enfin et surtout film gouverné par cette volonté mélodramatique de " lisibilité morale (Linda Williams) ${ }^{1}$ " par laquelle est permise, dans l'espace-temps clos d'un récit, une identification claire de ce que sont les valeurs troubles du bien et du mal ; ses personnages de victime et de vilain (Christine Collins, la 
police) ont une fonction équivalente à celles occupées par ceux de la princesse en détresse et de la belle-mère acariâtre dans nos légendes et dans nos mythes.

$6 \mathrm{Au}$ cœur du film, cependant, quand s'interrompt le cycle d'une fiction qui, par ses mécanismes dramatiques, énonce une taxinomie morale, manichéenne et rassurante, et que, symboliquement, s'écroule le paysage en carton-pâte de la banlieue de Los Angeles remembré sous un jour idyllique par le réalisateur, le spectateur découvre soudain un paysage calciné, un cimetière d'ossements - le ranch de Northcott - qui devient alors le lieu où se (re)joue le drame intérieur d'une mère qui veut croire encore que le pire n'est pas arrivé. Au-delà des diverses oppositions binaires autour desquelles il s'articule, Changeling est peut-être moins une histoire vraie que le rêve d'un autre possible. Une hypothèse qui donne l'échange.

7 Changeling (2008). États-Unis. Réalisation: Clint Eastwood. Scénario: J. Michael Straczynski. Images: Tom Stern. Montage : Joel Cox \& Gary Roach. Musique : Clint Eastwood. Décors : James Murakami. Interprètes : Jason Butler Harner, Jeffrey Donovan, Colm Feore, Angelina Jolie, Michael Kelly, John Malkovich, Amy Ryan.

\section{NOTES}

1. Lire à ce sujet Peter Brooks, The Melodramatic Imagination. Balzac, Henry James, Melodrama and the Mode of Excess, Londres et New Haven, Yale University Press, 1976, 1995, pp. 5-15 ; Linda Williams, Playing the Race Card. Melodramas of Black and White. From Uncle Tom to O.J. Simpson, Princeton et Oxford, Princeton University Press, 2001, 2002, pp 17-18.

\section{INDEX}

Thèmes : Trans'Arts 